\title{
Joint spatial variability of aerosol, clouds and rainfall in the Himalayas from satellite data
}

\author{
P. Shrestha and A. P. Barros \\ Pratt School of Engineering, Duke University, Durham NC 27708, USA \\ Received: 29 January 2010 - Published in Atmos. Chem. Phys. Discuss.: 12 February 2010 \\ Revised: 18 August 2010 - Accepted: 19 August 2010 - Published: 6 September 2010
}

\begin{abstract}
Satellite-based precipitation, Aerosol Optical Depth (AOD), Cloud Optical Depth (COD), and Aerosol Index (AI) data were used to characterize the linkages among landform and the intra-annual variability of aerosols, cloudiness and rainfall in the Himalayas using empirical orthogonal function (EOF) analysis. The first modes of AOD and AI show the presence of two branches of dust aerosol: over the Indus river basin and the Thar desert with a sharp west-east gradient parallel to the southern slopes of the Himalayas the Southern Branch; and the second against the slopes of the Tian Shan and over the Takla Makan desert in the Tibetan Plateau-the Northern branch. The third EOF mode of AOD accounts for about $7 \%$ of overall variance of AOD. It is attached to the foothills of the Himalayas east of the Aravalli range peaking in April-May-June followed by a sharp decrease in July during the first active phase of the monsoon. The first and second EOF modes of COD and precipitation show consistent patterns against the central and eastern Himalayas and along the ocean-land boundaries in western India and the Bay of Bengal. The break in cloudiness and rainfall between the winter and the monsoon seasons is captured well by the second EOF mode of COD and rainfall concurrent with the aerosol build up mode (AprilMay) over the region depicted by the third mode of AOD. The results show that the Aravalli range separates the two different modes of aerosol variability over northern India with dust aerosols to the west and polluted mixed aerosols to the east consistent with its role in regional circulation and precipitations patterns as per Barros et al. (2004) and Chiao and Barros (2007). SVD analysis between rainfall, COD and AOD showed a pattern of aerosol loading (resembling EOF3 of MODIS AOD) extending from $80^{\circ} \mathrm{E} \sim 90^{\circ} \mathrm{E}$ that peaks during the winter and pre-monsoon seasons and decays
\end{abstract}

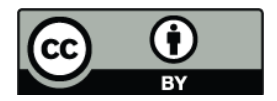

Correspondence to: P. Shrestha (prabhakar.shrestha@duke.edu) abruptly during the monsoon: the regions of aerosol buildup during the pre-monsoon season and the areas of high rainfall/cloudiness during the monsoon are collocated and have opposite signs suggesting aerosol-cloud-rainfall interaction. It is proposed that the third EOF of AOD maps the area where aerosol-cloud-rainfall interactions play an important role in the regional hydro-climatology.

\section{Introduction}

Satellite data from various platforms show that the Himalayas act as a barrier that separates a region of abundant aerosols in the Indo-Gangetic Plains (IGP) from the region of pristine air at high altitude in the Tibetan plateau (Gautam et al., 2009a, Fig. 1a). The accumulation of aerosol in this region can be explained in part by the blocking effect of incoming flows from the Indian subcontinent, but regionalscale circulations modulated by topography also play an important role. Previous studies by Barros et al. (2006), Chiao and Barros (2007), Barros et al. (2004) and Lang and Barros (2002) have shown that the space-time distribution of clouds and rainfall are strongly intertwined with the terrain in the region. The complex circulation patterns that arise from blocking lead to strong orographic enhancement of precipitation on the southern slopes of the Himalayas.

Lau et al. (2006) used GCM experiments to show that the mixture of black carbon and dust aerosols at higher altitude over the foothills of the Himalaya can act as an elevated heat source in the troposphere, strengthening the monsoon over northern India by intensifying convergence of moist air in the pre-monsoon season. In addition to this mesoscale dynamic effect, Fig. 1b illustrates another possible mechanism of aerosol scavenging by orographic enhancement of clouds and rainfall: aerosols act as condensation nuclei altering cloud drop distributions, and therefore cloud and precipitation microphysical processes, the so called indirect effect.

Published by Copernicus Publications on behalf of the European Geosciences Union. 


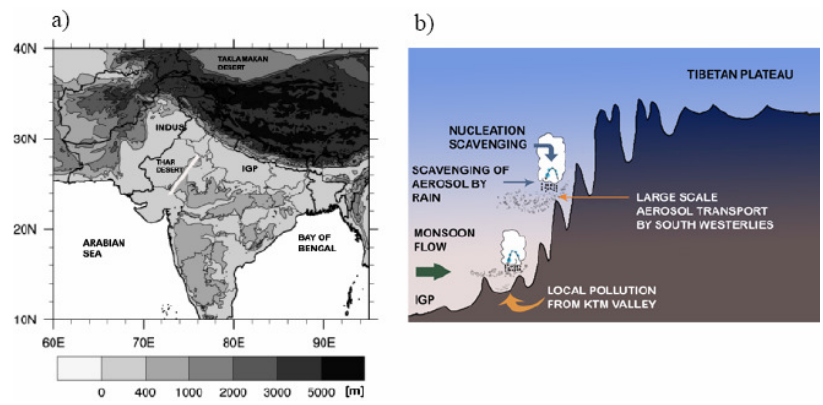

Fig. 1. (a): The Tibetan plateau and the Himalayas are unique features of Asia with the Indian Gangetic Plain (IGP) and Indus river basin on the southern slopes and Takla Makan desert on the northern slopes of the Tibetan plateau. Thar desert lies on the western slopes of the Aravalli range (straight white strip). Elevation contours are plotted at 400, 1000, 2000, 3000 and $5000 \mathrm{~m}$. Topography was obtained from the USGS gtopo30 data. b): Processing of aerosols by clouds along the North-South cross-section passing through Kathmandu Valley in Central Nepal.

Either via direct and, or indirect radiative forcing and, or via cloud microphysics (Ramanathan et al., 2001), the strong gradient in aerosol concentration appears therefore to be linked to the variability of orographic precipitation along the southern slopes of the Himalayas, thus collocating two of the world's steepest gradients of optical depth and topography in a region critical for the Asian summer monsoon.

Barros et al. (2004) showed that spatial variability of the diurnal cycle of convective activity as depicted by cloudiness in the southern-facing slopes of the Himalayas is strongly tied not only to the overall terrain envelope but also to the west-east succession of ridges and valleys, with the major river valleys that cut through the mountains connecting the Indian sub-continent and the Tibetan plateau controlling the overall spatial variability of clouds. Liu et al. (2008) could not find evidence of transport between northern India and the Tibetan plateau across the southern slopes of the Himalayas using CALIPSO (Cloud-Aerosol Lidar and Infrared Pathfinder Satellite Observations) data. However, their analysis was limited by the persistent cloud cover during the active phase of monsoon (Barros et al., 2004), which precluded detection of plumes associated with low-level flows aligned with major river valleys across the Himalayan range that permit transport from northern India to the Tibetan Plateau as shown by Barros et al. (2006) for two high-resolution simulations of monsoon onset depressions (also see MODIS Rapid Response Image Subset over Nepal).

In the Central Himalayas, Ramana et al. (2004) reported that the vertical aerosol extinction measured during February 2003 over the Kathmandu Valley showed two local maxima with the secondary maximum at $1.3 \mathrm{~km}$ a.g.1. (2.6 km a.m.s.l.). Both studies, Ramanathan and Ramana (2005) and Ramana et al. (2004), suggest that the primary elevated aerosol layers arises possibly from boundary layer mixing and elevated transport of aerosol from the Indo-Gangetic Plains (IGP), whereas the lower level peak was attributed to local pollution within the Kathmandu Valley (population 2 million). The local aerosol contribution was investigated by Regmi et al. (2003) who argued that boundary layer circulations caused by warm north-westerly flows over cooler shallow south-westerlies ( $250 \mathrm{~m}$ thick) in the Kathmandu Valley could explain the lower level peak. An alternative mechanism was proposed by Hindmann and Upadhyay (2002) who suggested that mountain-valley winds transported Kathmandu Valley pollution to the surrounding hilltops, thus redistributing low level pollutants to higher elevations where they could be picked up by synoptic flows. However, Carrico et al. (2003) found that the surface aerosol signature at Langtang (4000 m altitude, north of Kathmandu Valley) was similar to that associated with long range transport of dust, and they found no evidence of transport from local sources in the Kathmandu Valley. Their measurements of AOD in the Kathmandu Valley $(0.37 \pm 0.25)$ in the February-May period, that is the aerosol peak season, are also consistent with Ramana et al. (2004) (AOD in the range of 0.3 0.5). Recently Stone et al. (2009) also reported that carbonaceous aerosol concentrations measured during 2006 at Godavri site in Kathmandu Valley showed peak concentrations in late March and early April during the dry pre-monsoon season which is consistent with the annually occurring regional haze over the IGP. Further east, Shrestha et al. (2000) measured water soluble aerosols at Phortse $(4100 \mathrm{~m}$ a.m.s.l., Himalayan region of eastern Nepal), which is important from the point of view of aerosol-cloud microphysical interactions. They also report gradual build up of pollutants in the pre-monsoon season (peaking in April-May), which the authors linked to shifts in the large scale circulation, specifically transport from the Indian Gangetic Plains (IGP), and even farther west from the Thar desert. On the other side, Bonasoni et al. (2008) suggested that the monsoon-driven cleansing mechanisms of the atmosphere at pollution sources left locally suspended natural particles dominating the AOD at the ABC-Pyramid site (Khumbu Valley, Nepal, 5079 m a.m.s.l.) during the wet season indicating the after-effects of the dominant monsoon season in the region.

One limitation of field studies is the short duration and scattered distribution of surface point measurements that prevent data collection required to extract robust spatial patterns. Nevertheless, all field studies agree on the consistent presence of high concentration of aerosols at high altitude in locations far away from urban sources. Furthermore, the presence of elevated aerosol concentrations of remote origin at high altitudes beyond the edge of rainfall maxima signals the modulation of orographically enhanced precipitation processes upwind (Barros et al., 2004, 2006), and is consistent with transport from the northern Indian subcontinent to the High Himalaya and the Tibetan Plateau through both deep and shallow flow channels along the N-S oriented river valleys present over the Himalayas (as observed from 
MODIS Rapid Response Image Subset over Nepal in the premonsoon season of 2009).

Recently, observations of aerosols and rainfall from multiple satellite platforms have been used to characterize the relationship between aerosols, monsoon rainfall, and monsoon dynamics. Gautam et al. (2009a) present evidence suggesting a close link between pre-monsoon onset tropospheric warming in the IGP and increased atmospheric aerosol loading in the region, which could amplify the land-sea gradient and thus strengthen the initial active phase of the monsoon (June-July). Previously, Gautam et al. (2009b) pointed out that dust outbreaks over the Thar desert were the critical source of aerosol loading in the IGP prior to monsoon onset, and therefore interannual variability of the observed tropospheric warming discussed by Gautam et al. (2009a) would be dependent on the frequency and magnitude of dust activity in northwest India. Bollasina et al. (2008) found that increased aerosol concentrations in May lead to cloud suppression, with increased shortwave radiation reaching and warming the land-surface, thus proposing another pathway to strengthen the land-sea gradient prior to monsoon onset in addition to tropospheric warming. Trend analysis of rainfall during June over an almost twenty-year period showed statistically significant (though modest) increases in monsoon rainfall over regions in the Indian subcontinent that are concurrent with increased aerosol loading in the pre-monsoon period over time (Gautam et al., 2009c). In this manuscript, a concerted analysis of multisensor satellite data is performed to characterize the joint space-time modes of variability of rainfall and aerosol loading in the in the IGP with the objective of mapping the region where local aerosol-cloud-rainfall interactions are dominant vis-à-vis large-scale transport.

For this purpose, we present an assessment of the spatial mode of variability of aerosols and space-time modulation of rainfall using aerosol data products from the Total Ozone Mapping Spectrometer (TOMS) \& Moderate Resolution Imaging Spectroradiometer (MODIS), cloud products from MODIS, and rainfall data products from Tropical Rainfall Measuring Mission (TRMM). Section 2 provides an overview of the large scale circulations persistent over the region of study during the identified aerosol build up and decay period. Section 3 describes the remote sensing data used for this study. The EOF analyses of the fields are discussed in Sect. 4, and the joint spatial variability is discussed in Sect. 5 . Summary and conclusions are reported in Sect. 6.

\section{Regional scale circulation}

The Tibetan Plateau and the Himalayas are the dominant topographic features in Asia (Fig. 1a). During the winter season, the westerly jet stream is bifurcated by the Tibetan Plateau, and Shrestha et al. (2000) attributed changes in concentration of pollutants in aerosols at high altitude locations in the Himalayas to shifts in the orientation of
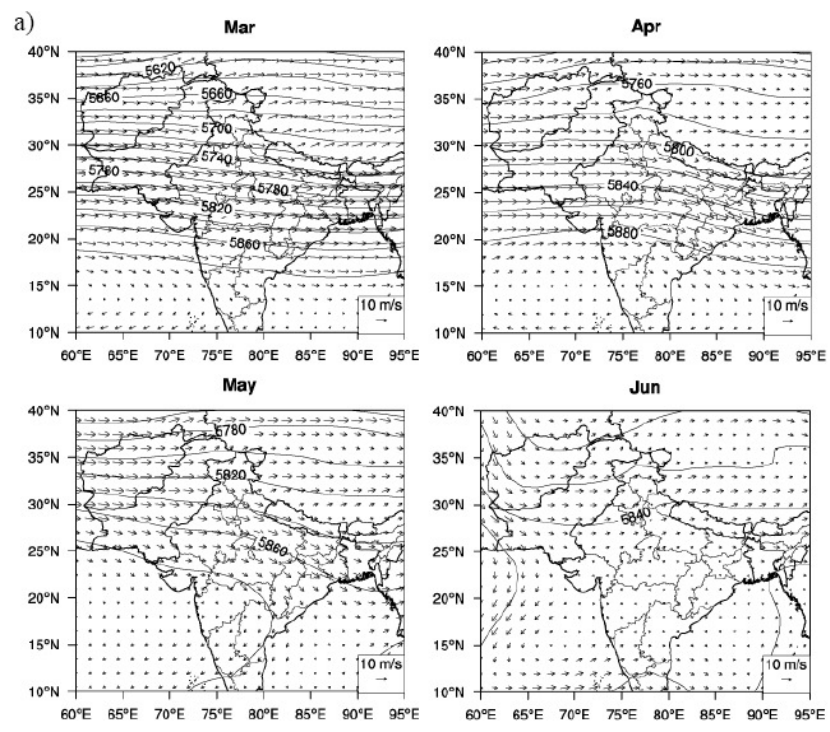

Fig. 2a. Mean geopotential height $(\mathrm{m})$ and horizontal wind $(\mathrm{m} / \mathrm{s})$ at $500 \mathrm{hPa}$ from 1998 to 2007 for the month of March, April, May and June. ERAInterim (http://www.ecmwf.int/research/era/do/get/ era-interim) dataset were used for the above analysis.

the southern branch between north-westerly (low concentrations) and south-westerly (high concentrations) orientations. Figure 2a shows the $500 \mathrm{hPa}$ mean horizontal winds and geopotential heights from ERAInterim (reanalysis product from the European Center for Medium Range Weather Forecasts - ECMWF at 1.5 degree resolution, http://www. ecmwf.int/research/era/do/get/era-interim) averaged over 10 years from 1998 to 2007 for the months of March, April, May and June. The mean wind profiles suggest that strong westerly wind dominates from March to April and gradually veers north from $18 \mathrm{~N}$ to $25 \mathrm{~N}$ turning north-westerly over Nepal and northern India. With the onset of Monsoon in June, the southern westerly branch of the jet stream falls apart, causing the main westerly flow to shift northward of the Tibetan plateau.

At lower levels, the buildup of the temperature gradient due to the development of a heat low (deepest in July) over the arid regions of Pakistan and north-west India during May pulls low level westerly flow from the Arabian sea and the Somali low-level jet (Findlater, 1969; Wu et al., 1999). Figure $2 \mathrm{~b}$ shows the $900 \mathrm{hPa}$ horizontal wind and geopotential height from the ERAInterim, averaged over 10 years from 1998 to 2007 for the months of March, April, May and June. The wind fields at higher altitudes where the surface geopotential is higher than the mean $900 \mathrm{hPa}$ geopotential were masked out. North-westerly flow is prevalent in March along the IGP. Note the two circulation patterns west and east of the Western and Eastern Ghat Mountains on the west and east coasts of the Indian subcontinent respectively that persist through April, as well as the strong low-level jet at $20 \sim 25 \mathrm{~N}$ 
crossing over the Thar desert into the IGP. The mean wind flow over the IGP weakens in the following months, whereas the westerlies further south strengthen and veer northeastward along the Eastern Ghats, and a weak convergence zone forms over the IGP below the Nepal-India border. Strong westerly flow is well established in the lower-half of the Indian subcontienent up to the Bay of Bengal. This westerly flow bifurcates at the Aravalli range turning south-westerly over the Thar desert, whereas it remains westerly, south of the Aravalli range. Dust storms in the IGP during the pre-monsoon season have been associated with dusts lifted mainly from the Thar desert and arid regions farther west along the path of the westerlies (Gautam et al. 2007). The observed blocking and convergence effects over the foothills of the Himalayas over Nepal create favourable conditions for the accumulation of both remote and local aerosol establishing sharp regional gradients.

\section{Satellite data}

Table 1 describes the various satellite datasets used for the study. Observations from the Moderate Resolution Imaging Spectroradiometer (MODIS) instrument aboard the Terra and Aqua satellites are used to study the variability of aerosol optical depth (AOD) over the region. Over land, MODIS aerosol retrieval is less accurate where albedo is high (e.g. deserts, free water-surfaces) compared to the region of low albedo (e.g. dark vegetation) (Kaufman et al., 1997; Hsu et al., 2004). To minimize the signal noise ratio (SNR), the algorithm (dark target approach) over land is applied to $10 \mathrm{~km} \times 10 \mathrm{~km}$ areas. The mean monthly aerosol optical depth used in this study is obtained from the MODIS Level 3 (L3) daily product for each month sorted into an $1^{\circ} \times 1^{\circ}$ equal angle grid. The daily L3 products contain statistics computed from Level 2 MODIS granules that span a $24 \mathrm{~h}$ period (see King et al., 2003; Hubanks et al., 2008).

To improve the retrieval over bright surfaces like deserts, an alternative AOD product is available using the Deep Blue retrieval algorithm, although it cannot handle the presence of clouds and therefore aerosol retrievals over cloudcontaminated scenes are not available (Hsu et al., 2006). Because the region of interest in this study has frequent cloudcover, this will also create gaps in the data. Hence, both the dark target approach and the deep blue algorithm will have gaps in the monthly mean data, one spatially stationary due to bright surfaces (desert), and the other spatially varying due to cloudy pixels. In order to eliminate the gaps in the MODIS AOD using the dark target approach algorithm, the MODIS Deep Blue aerosol retrieval $(550 \mathrm{~nm})$ at the same location and time was used to replace the missing AOD values over bright reflecting areas such as the Thar desert and the Taklaman desert. The AQUA data obtained from Deep Blue algorithm was available only from July 2002.
The aerosol index (AI) data from Total Ozone Mapping Spectrometer (TOMS) instrument was also used for the study:

$\mathrm{AI}=$

$-100\left\{\log _{10}\left[\left(I_{340} / I_{380}\right)_{\text {meas }}\right]-\log _{10}\left[\left(I_{340} / I_{380}\right)_{\text {calc }}\right]\right\}$

where $I_{\text {Meas }}$ is the backscattered radiance measured by TOMS at a given wavelength, and $I_{\text {calc }}$ is the radiance calculated using a radiative transfer model for a pure Rayleigh atmosphere (Hsu et al., 1999). The low value of near-UV albedo for land/water bodies combined with the large molecular scattering in this region of the spectrum allows for a robust determination of aerosol properties by TOMS. However, the retrieved quantities are sensitive to the height of UV-absorbing aerosol layer over the ground, but are not sensitive to the presence of non-absorbing aerosol, as well as smoke in the lowest $1 \mathrm{~km}$ of the atmosphere except for colored aerosols like mineral dust (Torres et al., 2002). Further, it is not possible to distinguish among different UVabsorbing aerosol types leading to AI errors if the aerosol types for different geographical regions are misclassified (see http://toms.gsfc.nasa.gov/news). Although the TOMS data from Earth Probe are available between 1996 and 2005, the time-window for this study was constrained to the period 1998 to 2005 for subsequent comparison against TRMM rainfall data which are available from 1998 onward. Due to calibration issues associated with sensor performance degradation, trend analysis of the data after 2001 is not recommended by the NASA TOMS science team (http://toms.gsfc. nasa.gov/news/news.html) (see also Gautam et al., 2009).

Precipitation estimates were obtained from the TRMM 3B-43 data product (http://mirador.gsfc.nasa.gov/cgi-bin/ mirador/presentNavigation.pl?tree $=$ project $\&$ project $=$

TRMM), which are derived from the combination of 3-hourly merged high-quality/IR estimates with the monthly accumulated Climate Assessment and Monitoring System (CAMS) or Global Precipitation Climatology Centre (GPCC) rain gauge analysis (Huffmnan et al., 2007). Monthly precipitation estimates gridded on $0.25^{\circ} \times 0.25^{\circ}$ global grids are available since 1998 .

Finally, MODIS Level 3 cloud optical depth (COD) was used to study the spatial and temporal modes of variability in cloudiness. The retrieval of cloud optical depth requires information about particle phase and cloud cover, and a radiative transfer model is used for the inversion algorithm. The retrieval is valid for single-layer, liquid water clouds, planeparallel geometry, and errors might arise for multiple layer clouds and when ice is present (King et al., 1998). Missing values (small number) in MODIS COD were filled by linear interpolation in time. Similar to the MODIS Level 3 aerosol products, the Level 3 cloud optical depth also contains the statistics derived from Level 2 products gridded at $1^{\circ} \times 1^{\circ}$ spatial resolution (see King et al. (1998) for more details). 
Table 1. List of data products used from different satellite platforms.

\begin{tabular}{llll}
\hline Sino. & Description & Satellite & Coverage \\
\hline 1 & Gridded daily aerosol index (AI) & Earth Probe TOMS & $01 / 98 \sim 12 / 05$ \\
2 & Gridded monthly AOD & Terra MODIS & $01 / 02 \sim 12 / 07$ \\
3 & Gridded monthly COD & Terra MODIS & $01 / 02 \sim 12 / 07$ \\
4 & Gridded monthly rainfall & TRMM 3B43 (V6) & $01 / 98 \sim 12 / 07$ \\
\hline
\end{tabular}

\section{EOF analysis}

EOF analysis when applied to a space-time dataset can be used to decompose the observed variability into a set of orthogonal spatial patterns (EOFs), which are invariant in time, and a set of time series, the expansion coefficients (ECs), which are invariant in space (e.g. North et al., 1982; Behera et al., 2003; Perry and Neimann, 2007; Giovanntone and Barros, 2008; among many others). In this study, we conducted EOF analysis using the covariance method (Von Storch and Zwiers 1999) to study temporal and spatial anomalies of rainfall, aerosols and cloudiness over a larger spatial domain covering the IGP in the south to the Tibetan plateau in the North. Note that, due to the relatively short duration $(<10$ years) of the data sets analyzed here, interannual variability can be detected through the temporal variability of the EOF expansion coefficients but a robust statistical characterization is not possible. Thus, the discussion of results is focused on the annual/seasonal cycles.

\subsection{Aerosol variability}

The first EOF mode (EOF 1) from MODIS and TOMS explain $50 \%$ and $54 \%$ of the overall AOD and AI field variances respectively (see Figs. 3 and 4). Both modes show the presence of two branches of the dust aerosol distribution: the southern branch (SB) over the Indus river basin and Thar desert north-west of Aravalli range, with a sharp westeast gradient parallel to the southern slopes of the Himalayas; and the northern branch against the slopes of the Tian Shan and over the Takla Makan desert in the Tibetan Plateau. The northern branch is associated with the active dust storms in the Takla Makan desert in the Xinjiang region of Western China (Figs. 1b and 5a). A sandy haze covers most of the oval shaped desert, which sits in a depression between two high mountain ranges: the Tian Shan to the north, and the Kunlun to the south. Earlier, Lau et al. (2006) and Lau and Kim (2006) noted that the two branches of AOD should be composed primarily of dust aerosols originating from the deserts, whereas carbonaceous aerosols from biomass burning over northwestern India and Pakistan should be present in the chemical composition of the Southern Branch. Blocking of incoming air masses by the mountain ranges in the north and west of the Indus river basin (Fig. 1a) is primar-
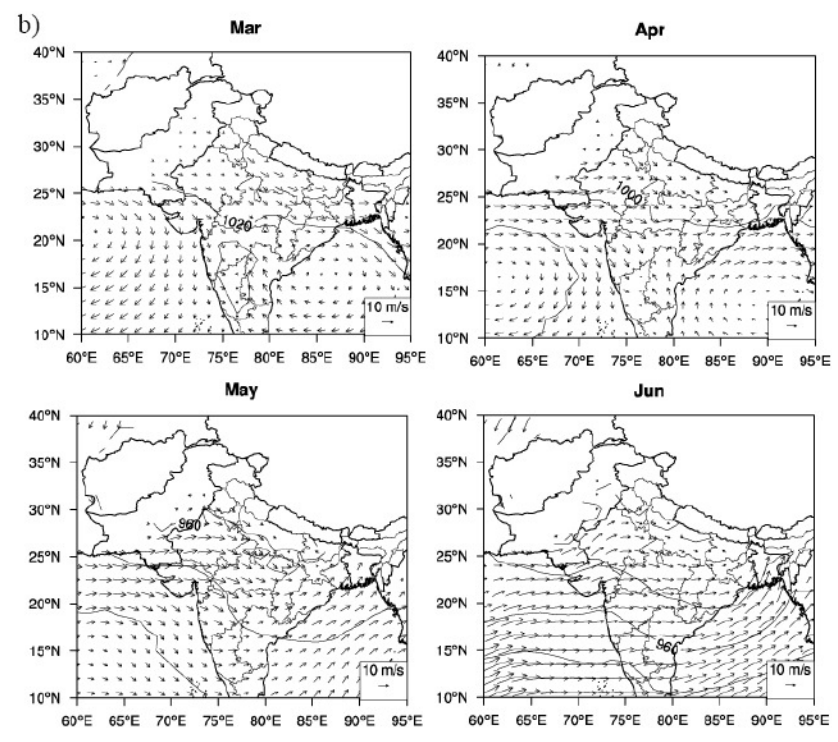

Fig. 2b. Mean geopotential height $(\mathrm{m})$ and horizontal wind $(\mathrm{m} / \mathrm{s})$ at $900 \mathrm{hPa}$ from 1998 to 2007 for the month of March, April, May and June. ERAInterim (http://www.ecmwf.int/research/era/do/get/ era-interim) dataset were used for the above analysis. Locations where the surface geopotential height is higher than the $900 \mathrm{mb}$ geopotential height have been masked out.

ily responsible for the buildup of the southern branch. This blocking creates a favorable spot for aerosol accumulation, which is sustained by the dust originating from the Thar desert and arid regions in Pakistan, Afghanistan and farther west. Figure $5 b$ shows the MODIS visible image of a storm that stretches for over 1000 kilometers (about 620 miles) from central Pakistan into northern India in June 2005, which exhibits morphology typical of dust storms in the region in spring and summer. The heat low over the desert results in strong convergence inducing dry convection that carries surface dust aloft to be subsequently transported away by the prevailing winds (see the dust plume in Fig. 5b). The blocking effect of the terrain is evident from the sharp W-E gradient of aerosol concentration along the foothills of the Himalayas in the southern branch (SB) of EOF1 for TOMS AI and MODIS AOD $\left(68^{\circ} \mathrm{E}\right.$ to $\left.80^{\circ} \mathrm{E}\right)$. The MODIS SB EC1 indicates that AOD starts building up in April-May, peaks in July, and is followed by a decline in August and September 


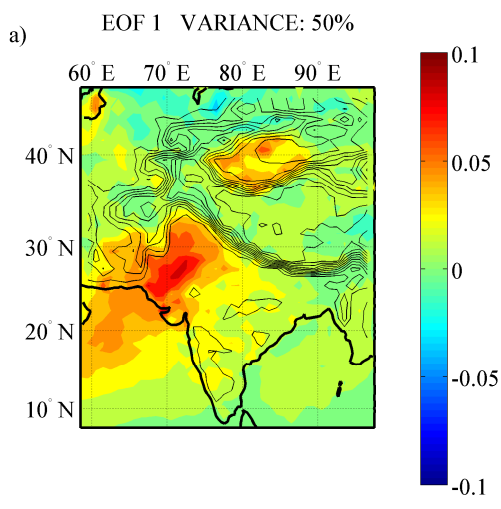

b)

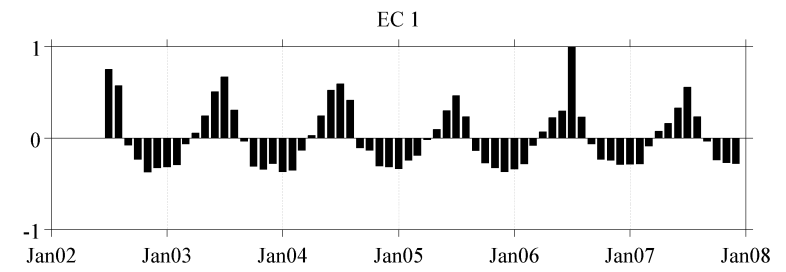

Fig. 3. EOF 1 (a) and EC1 (b) computed from MODIS monthly aerosol optical depth (AOD) using the combined product of dark target approach and deep blue algorithm. [Terrain contours are plotted at $500 \mathrm{~m}$ interval from 500 to $8000 \mathrm{~m}$.

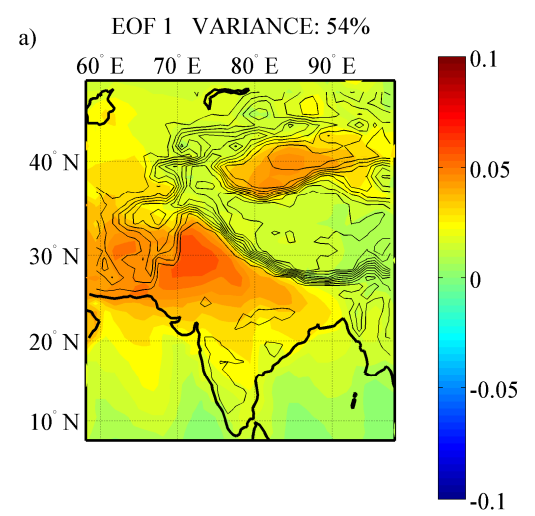

b)

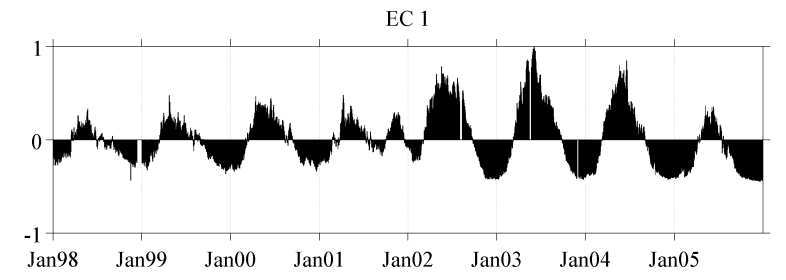

Fig. 4. EOF 1 (a) and EC1 (b) computed from TOMS daily aerosol index (AI) indicate a dominant mode over the Indus river basin and Thar desert with a sharp west-east gradient along the southern slopes of the Himalayas.

consistent with the retreat of the monsoon. Persistent build up of aerosol in May-June-July is present over the six year span of the study (2002-2007). This aerosol build up and the
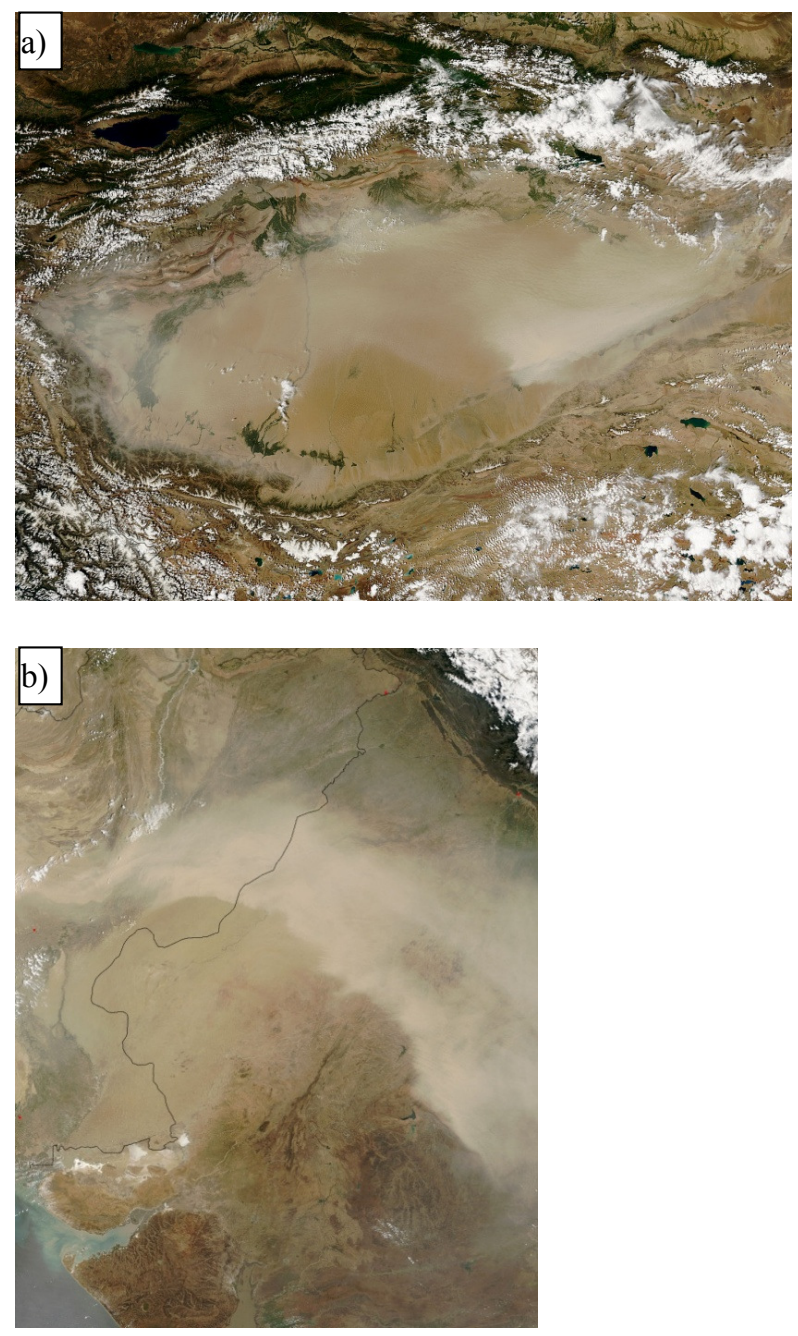

Fig. 5. MODIS image of dust storm over Takla Makan desert, northern slopes of Tibetan plateau (a) and Thar desert, north-western part of India (b), source: VISIBLE EARTH NASA Image.

decline in the second-half of the monsoon is explained by the strengthening and decay phases of the low level westerly flow that can bring pollutants all the way from the east coast of Africa and the Middle East (Lau et al., 2006).

The second mode (EOF2) of MODIS AOD shows a spatial pattern with maximum amplitude in the Takla Man desert over the months of March-April-May (see EC2), and accounts for $15 \%$ of the overall variance (Fig. $6 \mathrm{a}, \mathrm{c}$ ). The southern branch appears with peaks in the northwest sector of the Indus river basin downwind of the Thar desert and extends eastward in the IGP aligned with the slopes of the Himalayas. EC2 (Fig. 6c) displays two distinct peaks in aerosol build up that correspond to the bimodal peaks of the area-averaged time-series of AOD over the Takla Man desert $\left(78-81^{\circ} \mathrm{E}\right.$, $37-39^{\circ} \mathrm{N}$ ), one during the pre-monsoon season and another peak in the monsoon season. 

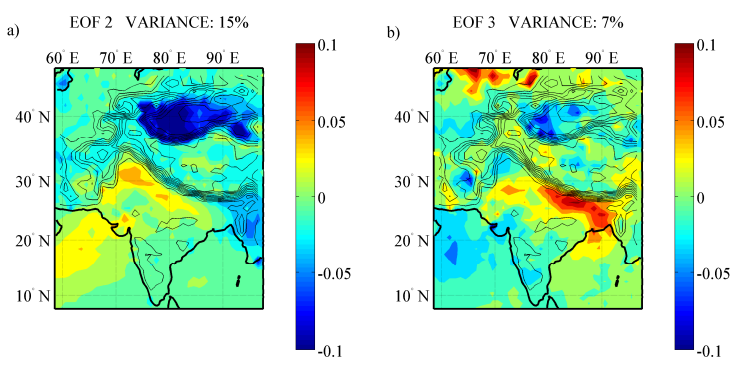

c)

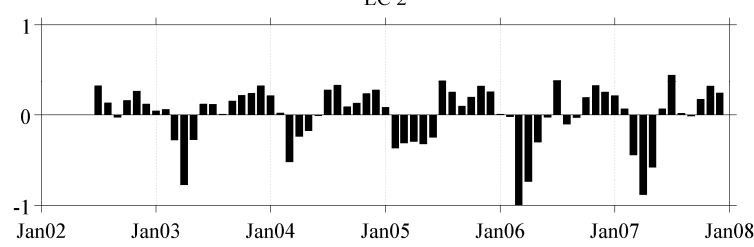

d)

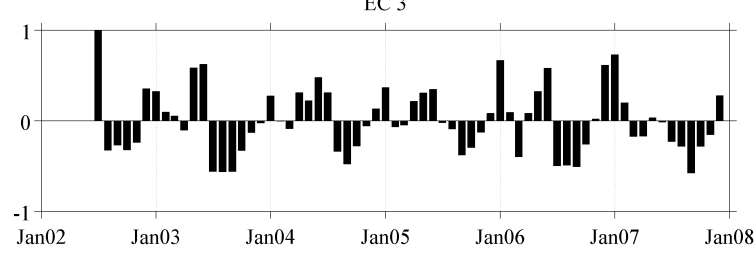

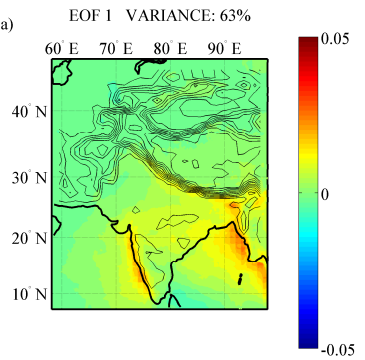

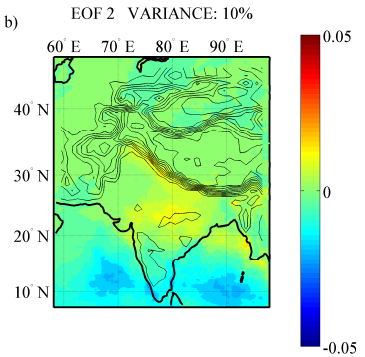

c)

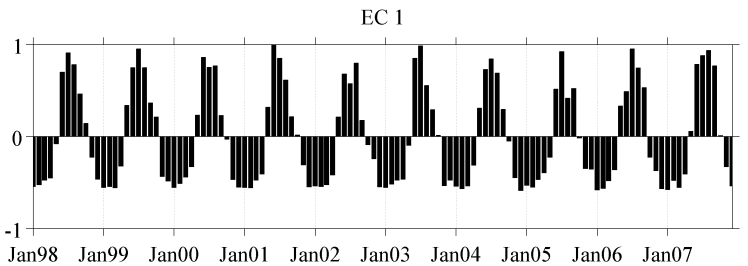

d)

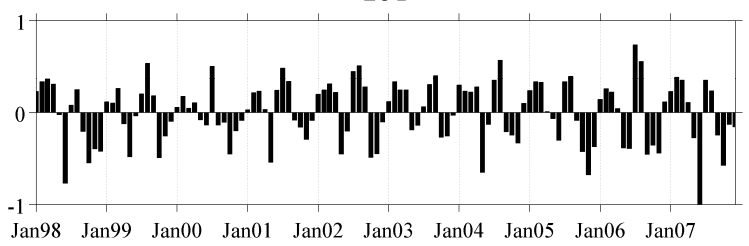

Fig. 7. (a, b) EOF 1 and EOF 2 obtained from the TRMM monthly accumulated rainfall product. (c, d) EC1 and EC2 of the corresponding EOF1 and EOF2 of the TRMM rainfall respectively.

\subsection{Rainfall and cloud variability}

Strong gradients of cloudiness and rainfall are aligned along the Western Ghats in the SW of India, the SW coastlines of Bangladesh and Burma, and the southern slopes of the Himalayas. The modes of rainfall and cloudiness are highly correlated indicating clouds as tracers of the anomalous monsoon rainfall. The first EOF mode (EOF 1) of TRMM 3B-43 rainfall (Fig. 7) explains $63 \%$ of the overall variance and captures the strong gradient of monsoon rainfall prevalent over the Western Ghats and near the Bay of Bengal, as well as a substantial amount of rainfall in Central India. The scarcity of monsoon rainfall over the arid region of NW India is concurrent with the strong gradient of aerosol build-up in the region which peaks in July as per the first EOF mode of MODIS AOD and TOMS AI. As discussed before, the convective activity is confined to the east of the Aravalli range during the monsoon. The first EOF mode of rainfall displays a strong gradient aligned with the lower foothills of the Himalayas during the JJAS period consistent with the orographic modulation of low level depressions that propagate westward from the Bay of Bengal and produce large rainfall (Lang and Barros, 2002). In the analysis of summer monsoon rainfall in 1999, 2000 and 2001 in the Marsyangdi river basin in Central Nepal, Lang and Barros (2002) noted that 
the spatial distribution of precipitation was primarily due to the specific track of monsoon depressions originating from the Bay of Bengal, specifically whether they veer toward or away of the Himalayas. On the other hand, large differences in rainfall (up to a factor of 8 ) were also observed within a high density network with raingauges placed within $1-2 \mathrm{~km}$ from each other illustrating the importance of small scale orographic effects in modulating rainfall. Although the EOF analysis of monthly TRMM3B-43 rainfall data used here are not able to discern the active and break phases of monsoon that take place at sub-monthly time-scales (Krishnamurthy and Shukla, 2000; Barros et al., 2004), the presence of large spatial patterns of the same sign in northern India and the southern foothills of the Himalaya indicates that the dominant mode of the JJAS seasonal variation of rainfall is robust.

The first EOF mode (EOF1) of the MODIS Cloud Optical Depth (COD, Fig. 8) explains 35\% of the variance and shows cloudiness associated with the monsoon over the Western Ghats of southwest India and the SW coastlines of Bangladesh and Burma. Variation over the southern slopes of the Himalayas is only apparent in the second mode (EOF2) of MODIS COD corresponding to $12 \%$ of the variance consistent with the highly transient nature of regional circulation in the region. The EOF2 pattern is linked to westerly disturbances propagating eastward along the foothills of Himalayas during the winter and the dominant monsoon season (JJAS) (Shrestha, 2000; Kansakar et al., 2004). EOF2 also shows distinct cloudiness patterns in the Northern India Convergence Zone (NICZ, a convergence zone constrained to the Ganges valley and the Himalayan range, Barros et al., 2004). In northern India, EOF2 of COD is positive while EC2 is negative in May and October-November. This implies less cloudiness in May and October-November in northern India consistent with the the expansion and retreat of cloudiness patterns over the NICZ and the latitudinal excursions of the ITCZ (Intertropical Convergence Zone) during the pre and post-monsoon seasons. In the ITCZ the May cloudiness pattern precedes the onset of the summer monsoon while the October-November cloudiness is associated with the retreat of the monsoon. In fact, the first two modes of the rainfall (Fig. 7) and COD (Fig. 8) capture the northward movement of the Indian monsoon: the first mode corresponding to the annual cycle of the monsoon proper, and the second mode corresponding to the semi-annual cycle showing the southern rain band in the spring (before the monsoon onset) and in the fall (after the monsoon retreat). EOF3 of MODIS COD (not shown) explains $8 \%$ of all variance and exhibits a spatial pattern that is consistent with deep convection activity in the region of highest intensity of lightning strikes detected by the Lightning Imaging Sensor (LIS, http://thunder.msfc.nasa.gov/) in the Manhadi Valley against the topography of the Eastern Ghats, in the Bramaputhra valley against the Garo Khasi Mountains, and in the mountainous region of the Indus river valley in the western $\mathrm{Hi}$ malayas. Although consistently positive in March and April when lightning activity peaks up in the region, EC3 is characterized by very large interannual variability.

The temporal correlation of the ECs between TRMM rainfall/MODIS AOD and MODIS COD/AOD were also examined. The highest correlation $(r=0.86)$ is found among the first modes of MODIS AOD and COD and between the first modes of MODIS AOD and TRMM precipitation $(r=0.85)$ with a lag of 1 month and correlation length of five-months. Further, a survey of the temporal evolution of the standardized anomalies of ECs of the first modes of MODIS AOD and TRMM rainfall and MODIS AOD and COD indicates that the sign is the same (i.e., the anomalies are in phase) about $50 \%$ of the time with maximum agreement for the month of May. Although the data sets are short at present to elaborate on inter-annual variability effects, the anomalies do suggest a positive relationship between the monsoon rainfall and the development of the first mode of MODIS AOD. The first spatial mode (EOF1) of clouds and the rainfall are aligned along the Bay of Bengal and the Western Ghats of India, and the first spatial mode (EOF1) of AOD is aligned NW of Aravalli range, these modes reflect different source areas for moisture (ocean) and aerosol (the middle-east, deserts and urban areas in northwest India), but both are modulated by the same regional circulation patterns (Lau et al., 2006; Barros et al., 2004). Regarding the standardized anomalies of the first mode of MODIS AOD and the second mode of TRMM rainfall, the most consistent agreement is in June and July: that is, the increase in monsoon rainfall over Central India and the southern slopes of Himalayas is concurrent with the increase in AOD NW of the Aravalli range. Thus, the same large-scale dynamics drive aerosol and moisture transport in the region.

\section{Joint variability}

The coupled modes of variability between the time series of two fields were analyzed by singular value decomposition (SVD) of the covariance matrix between the two fields. The relevant property of the left and right singular vectors obtained from SVD is that they maximize covariance and hence are the patterns themselves. The expansion coefficients $(a, b)$ are obtained as the projection of the fields on the left and right singular vectors respectively (see Bretherton et al. 1992, Storch and Zwiers 1999 for detailed discussions). The analysis was applied to pairs of TRMM precipitation, MODIS AOD and COD for a time span of six years from 2002 to 2007. The TRMM precipitation data $\left(0.25^{\circ} \times 0.25^{\circ}\right)$ was interpolated to the same grid $\left(1^{\circ} \times 1^{\circ}\right)$ of the MODIS products. Further, to identify temporal relationships among the fields, the correlation of the expansions coefficients of the pair of patterns $\left(f_{x}, f_{y}\right)$ at different lags was calculated (Table 2). All the patterns exhibited a strong correlation at zero lag. 
Table 2. Cross-correlation between the expansion coefficients of the pair of patterns TRMM Precipitation-MODIS AOD.

\begin{tabular}{lrrrrrrrr}
\hline Lag & -3 & -2 & -1 & 0 & 1 & 2 & 3 & Covariance explained \\
\hline & 0.16 & 0.60 & 0.84 & 0.88 & 0.58 & 0.16 & -0.29 & $96 \%(\mathrm{a} 1, \mathrm{~b} 1)$ \\
& -0.56 & -0.18 & 0.38 & 0.71 & 0.44 & 0.14 & -0.05 & $3 \%(\mathrm{a} 2, \mathrm{~b} 2)$ \\
\hline \multirow{2}{*}{ MODIS COD and MODIS AOD } & & & & & & & & \\
\hline Lag & -3 & -2 & -1 & 0 & 1 & 2 & 3 & Covariance explained \\
\hline & -0.20 & -0.12 & -0.05 & 0.27 & 0.24 & 0.15 & 0.16 & $87 \%(\mathrm{a} 1, \mathrm{~b} 1)$ \\
& -0.08 & 0.32 & 0.68 & 0.87 & 0.71 & 0.45 & 0.04 & $10 \%(\mathrm{a} 2, \mathrm{~b} 2)$ \\
\hline
\end{tabular}

\subsection{TRMM precipitation-MODIS AOD}

The first pair of patterns has a maximum squared crosscovariance of $96 \%$ and resembles the first two EOF modes of MODIS AOD and the first mode of TRMM rainfall (Fig. 9, Table 2). The main features of the TRMM precipitation are the heavy rainfall over the Western Ghats of India, Bay of Bengal, and a narrow strip of precipitation along the Himalayas associated with the strong monsoon season. The MODIS AOD shows a dominant mode in the Indus valley with sharp W-E gradient running parallel to the southern slopes of Himalayas. But this pair of patterns is not exactly collocated and has the same signs i.e. similar (in phase) build up and decay cycles. These spatial modes reflect different source areas for moisture and aerosols, with the same large scale dynamics driving the aerosol and moisture transport into the region. The patterns and the lag coefficients are consistent with the timing and spatial signature of monsoon dynamics. The expansion coefficients of the first pair of patterns show a strong correlation at zero lag during the monsoon season (Fig. 10a). The second pair of patterns has a squared cross-covariance of only $3 \%$, though the morphology of the spatial features resembles the EOF2 of TRMM rainfall and EOF3 of MODIS AOD. Notice in particular the MODIS AOD pattern extending from $80^{\circ} \mathrm{E} \sim 90^{\circ} \mathrm{E}$ that peaks during the winter and pre-monsoon season and decays abruptly during the monsoon season (Fig. 10a (Pattern 2), Table 2). The areas of anomalous aerosol buildup during the pre-monsoon season and the areas of high rainfall during the monsoon are collocated and have opposite signs indicating scavenging of aerosols by rainfall (see Fig. 9).

\subsection{MODIS COD and AOD}

Similar to the results obtained for TRMM Precipitation and MODIS AOD, the first pair of covariance patterns for MODIS COD and AOD has the maximum squared covariance of $87 \%$, and the MODIS AOD pattern resembles its first mode (Fig. 11). The cloudiness in the first pattern however differs from the first mode of MODIS COD. The time series of the first pair of patterns between COD and AOD
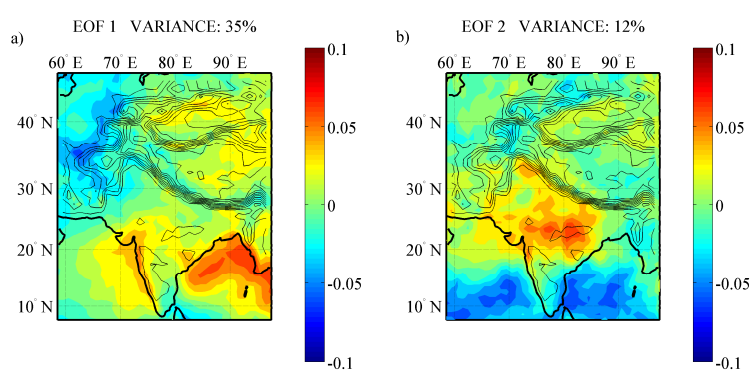

c)

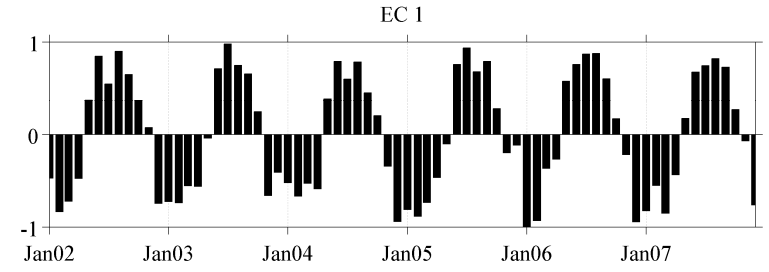

d)

EC 2

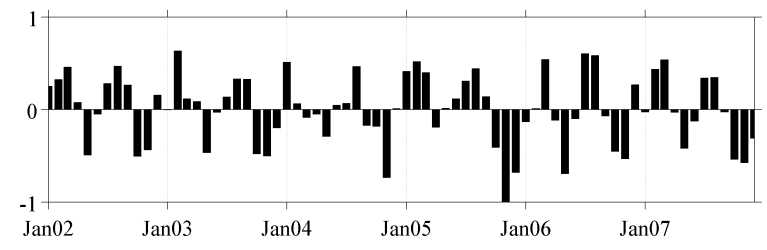

Fig. 8. (a, b) EOF 1 and EOF 2 obtained from the MODIS COD product. (c,d) EC1 and EC2 of the corresponding EOF1 and EOF2 of the MODIS COD respectively.

(Fig. $10 \mathrm{~b}$ ) indicate a persistent presence of cloudiness along the Bay of Bengal and Himalayas with a weak signal of cloudiness over the Western Ghats. On the other hand, the aerosol loading is also present throughout the year along the southern and northern slopes of the Tibetan plateau but it does exhibit an annual cycle with peaks during the monsoon. These two signals appear to explain the maximum cross-covariance, although the time series do not have high correlation (Table 2). Unlike the gradual build up and decay of the annual cycle of precipitation (Fig. 10a, pattern 1 ), cloudiness is present throughout the year but increases 

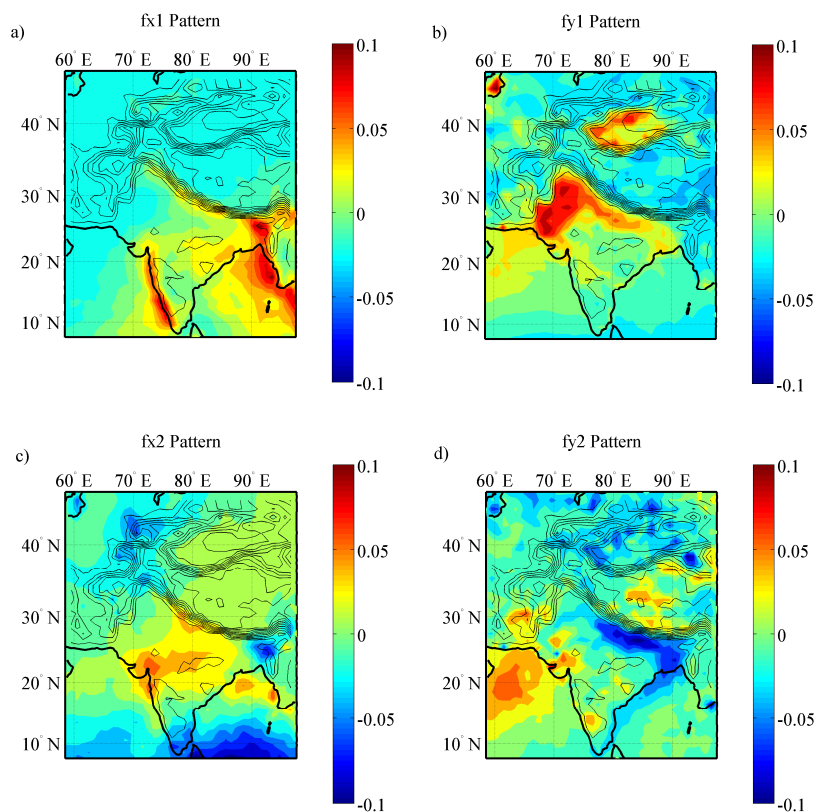

Fig. 9. The first two spatial patterns of TRMM precipitation $\left(f_{x 1}\right.$, $\left.f_{x 2}\right)$ and MODIS AOD $\left(f_{y 1}, f_{y 2}\right)$ that explains the maximum covariance between the two fields.

dramatically during the monsoon (Fig. 10b, pattern 2). The first modes of TRMM rainfall, MODIS AOD and MODIS COD explain $63 \%, 50 \%$ and $35 \%$ respectively of the total variance with comparatively lowest magnitude for the COD. SVD analysis of TRMM rainfall and MODIS COD (not shown here) show spatial patterns consistent with TRMM EOF1 and EOF2. The temporal variability of the coefficients of the second patterns exhibit higher negative values for $\mathrm{COD}$ compared to rainfall in the late fall and winter season, consistent with a strong regional increase of cloudiness without significant rainfall at that time of the year. This signal was highly dominant in the NW part (58-75 E, and 30-47 N) and appears in the first EOF of COD. AOD and rainfall on the other hand show a distinct monsoon peak only. This difference in seasonal behavior provides a possible explanation for the different spatial patterns of rainfall and COD associated with similar AOD (Figs. 9 and 11).

The second pair of patterns explains $10 \%$ of the squared cross-covariance with a strong correlation between the timeseries of the patterns (Table 2). It shows the distinct monsoon signal with cloudiness over the Western Ghats, Bay of Bengal and Eastern Ghats, and it is coupled with the built up of aerosol over the Arabian sea. The expansion coefficient of the MODIS COD for the second pair of patterns explains the cloudiness over the Western and Eastern Ghats of India, Bay of Bengal and northern India along the IGP during the summer monsoon and the cloudiness over the Himalayan topography, north-eastern India and the northern Pakistan, and near the ITCZ during the remainder of the year (Fig. 10b). Sim- a)
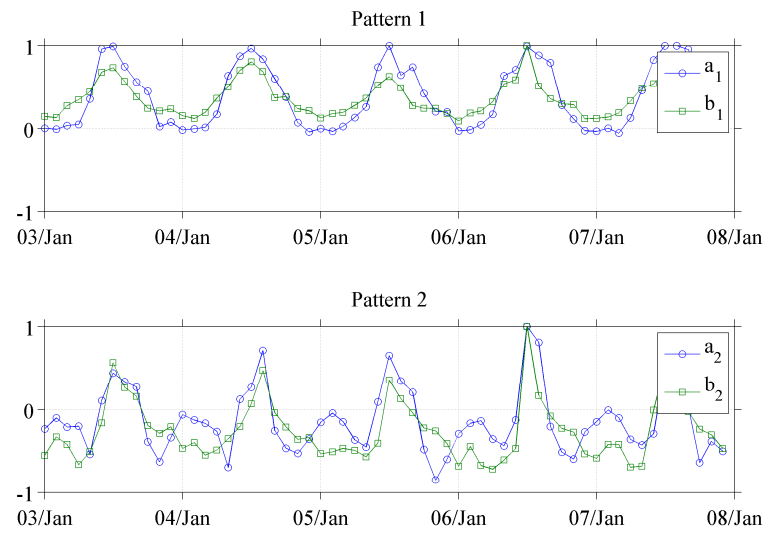

b)

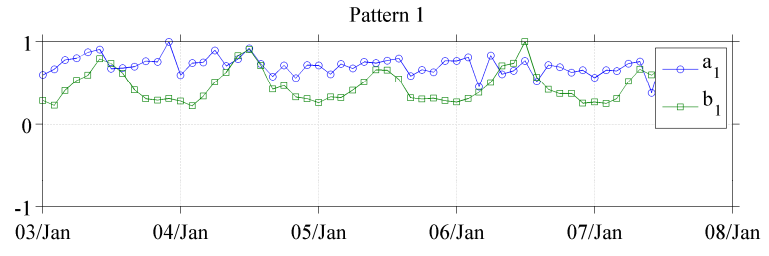

Pattern 2

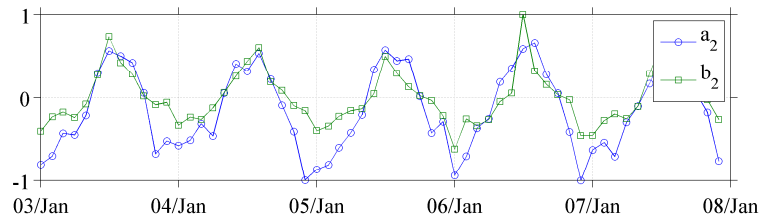

Fig. 10. The time series of the expansion coefficients between the pair of patterns: (a) Spatial patterns of TRMM precipitation and MODIS AOD, (b) Spatial patterns of MODIS COD and MODIS AOD.

ilar to the second pair of TRMM precipitation and MODIS $\mathrm{AOD}$, an inverted L-shaped pattern of aerosol is visible in the north-eastern sector of India bounded by the Himalayas over Nepal. This aerosol pattern peaks during the winter and premonsoon seasons and is collocated with the areas of cloudiness along the IGP but with opposite sign (see Fig. 11), thus suggesting possible interaction with the clouds before and during the onset of the monsoon.

\section{Summary}

The objective of this study is to identify the domain of joint space-time variability of aerosols, clouds and rainfall along the south facing slopes of the Himalayas. The spacetime patterns of the first EOF modes of satellite-based precipitation (TRMM 3B-43), Aerosol Optical Depth (AOD), Aerosol Index (AI), and Cloud Optical Depth (COD) reflect large-scale circulation patterns modulated by the Himalayan range. Indeed, the overall EOF spectra (Fig. 12) are consistent with the results pointed out by Barros et al. (2004) 

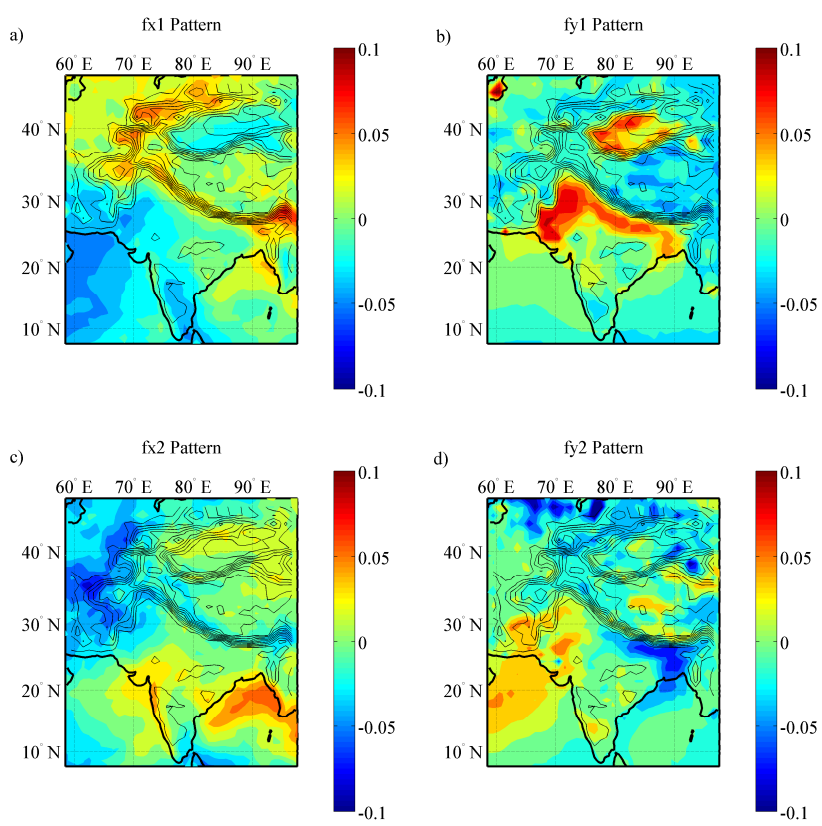

Fig. 11. The first two spatial patterns of MODIS COD $\left(f_{x 1}, f_{x 2}\right)$ and MODIS AOD $\left(f_{y 1}, f_{y 2}\right)$ that explains the maximum covariance between the two fields.

for the Himalayas and by Giovannetone and Barros (2009) for the Andes with the first EOF mode explaining 45-55\% of the overall variance of all observations in continental regions where orography plays the dominant role in organizing regional circulation and transport patterns.

Analysis of the regional mean flow shows that the blocking and convergence effects over the Indus river basin and Thar desert and along the foothills of the Himalayas over Nepal create favourable conditions for the accumulation of both remote and local aerosol establishing sharp regional gradients, which is consistent with the spatial modes of aerosol variability obtained from EOF analysis. Two different modes of aerosol buildup that develop east and west of the Aravalli range can be clearly identified from the analysis of the spacetime patterns defined by EOFs and ECs. The spatial pattern of the third mode of AOD is collocated with the first and second mode of TRMM precipitation and MODIS COD respectively. The first EOF modes of COD and precipitation show consistent patterns against the central and eastern Himalayas and the Western Ghats and along the ocean-land boundaries in western India and the Bay of Bengal. The break in cloudiness between the winter and the monsoon captured by the second EC of MODIS COD coincides with the aerosol build up mode (April-May) over the region corresponding to the transition between distinct modes of cloudiness from cold (winter) to warm (monsoon) seasons. These results confirm previous work regarding the relationship between the anomalous aerosol buildup during the months of April and May and the pre-monsoon rainfall regime by aerosol cloud

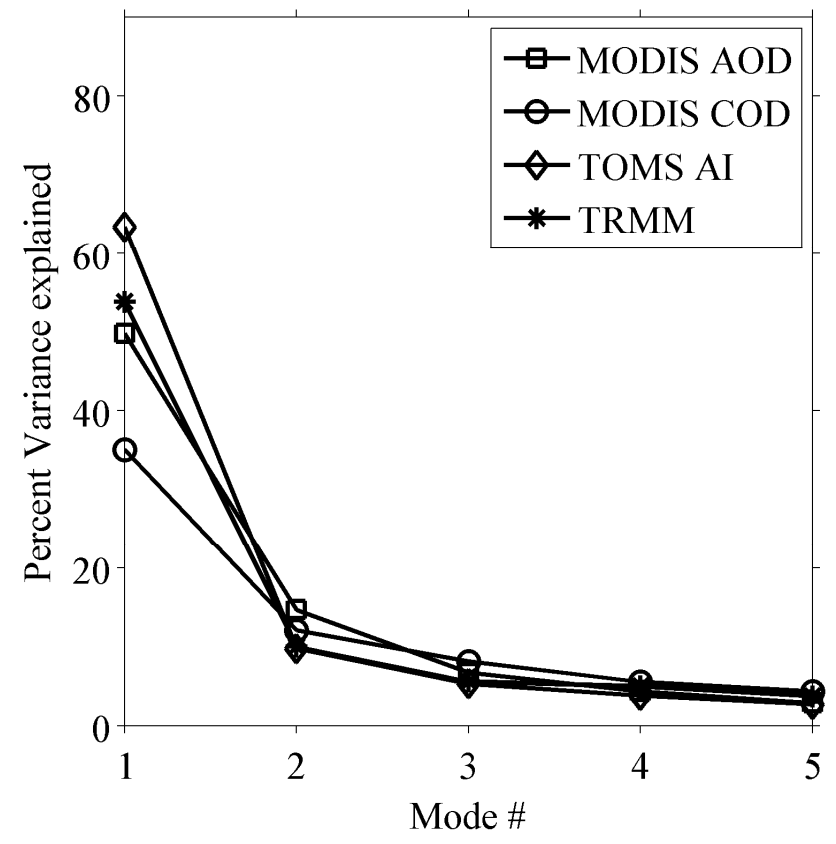

Fig. 12. Distribution of the relative contribution of the first 5 modes to the overall spatial variance for MODIS AOD, MODIS COD, TOMS AI and TRMM precipitation.

interaction. Earlier, Lau et al. (2008) provided evidence for aerosol indirect effect over the IGP using the MODIS derived cloud effective radius and AOD by showing smaller effective radius of cloud drops less than 10um over the regions of polluted cloud. In addition, Tripathi et al. (2007) examined the MODIS AOD and liquid/ice cloud effective radius from 2001 to 2005 over the IGP. In their study, for increasing cloud cover fraction, best correlation between liquid/ice cloud effective radius and AOD was obtained during the pre-monsoon season, suggesting an increase in indirect effect with increase in cloud cover during the pre-monsoon season. The strongest correlation was obtained when cloud fraction was $0.6 \sim 0.8$ but then it decreased for higher values, suggesting a possible threshold for the aerosol indirect effect. The SVD analysis between rainfall, COD and AOD showed the presence of aerosol loading (resembling EOF3 of MODIS AOD) extending from $80^{\circ} \mathrm{E} \sim 90^{\circ} \mathrm{E}$ that peaks during the winter and pre-monsoon season and decays sharply during the monsoon season: the areas of anomalous aerosol buildup during the pre-monsoon season and the areas of high rainfall/cloudiness during the monsoon are collocated and have opposite signs suggesting aerosol-cloud-rainfall interaction. This study identifies an area focused on Central Nepal including the IGP where there is consistent spatio-temporal agreement among aerosol, cloudiness and rainfall variability both in the pre-monsoon and monsoon seasons, and thus where the aerosol indirect effect is likely to be important in the region. 
Acknowledgements. This research was funded in part by NASA Earth System Science Fellowship with the first author and by NASA grant NNX07AK40G with the second author. The data for this study was obtained from the Giovanni online data system, developed and maintained by the NASA Goddard Earth Sciences (GES) Data and Information Services Center (DISC). The authors are thankful to the Reviewers for their comments and suggestions.

Edited by: J. J. Schauer

\section{References}

Barros, A. P., Kim, G., Williams, E., and Nesbitt, S. W.: Probing orographic controls in the Himalayas during the monsoon using satellite imagery, Nat. Hazards Earth Syst. Sci., 4, 1-23, doi:10.5194/nhess-4-1-2004, 2004.

Barros, A. P., Chiao, S., Lang, T., Burbank, D., and Putkonen, J.: From weather to climate - Seasonal and interannual variability of storms and implications for erosion processes in the Himalaya, Geol. Soc. Amer. Spec. Pap., 398, 17-38, 2006.

Behera, S., Rao, S., Saji, H., and Yamagata, T.: Comments in "A cautionary note on the interpretation of EOFS", J. Climate, 16, 1087-1093, 2003.

Bonasoni, P., Laj, P., Angelini, F., Arduini, J., Bonafe, U., Calzolari, F., Cristofanelli, P., Decesari, S., Facchini, M. C., Fuzzi, S., Gobbi, G. P., Maione, M., Marinoni, A., Petzold, A., Roccato, F., Roger, J. C., Sellegri, K., Sprenger, M., Venzac, H., Verza, G. P., Villani, P., and Vuillermoz, E.: The ABC-Pyramid Atmospheric Research Observatory in Himalaya for aerosol, ozone and halocarbon measurements, Sci. Total Environ., 391, 252-261, 2008.

Bretherton, C. S., Smith, C., and Wallace, J. M.: An Intercomparison of Methods for Finding Coupled Patterns in Climate Data, J. Climate, 5, 541-559, 1992.

Bollasina, M., and Nigam, S.: Absorbing Aerosols and Summer Monsoon Evolution over South Asia: An Observational Portrayal, J. Climate, 21, 3221-3239, 2008.

Carrico C. M., Bergin, M. H., Shrestha, A. B., Dibb, J. E., Gomes, L., and Harris J. M.: The importance of carbon and mineral dust to seasonal aerosol properties in the Nepal Himalaya, AE Intl.Asia, 37, 2811-2824, 2003.

Chiao, S. and Barros, A. P.: A Numerical Study of Hydrometeorological dryline in Northwest India during the monsoon, J. Meteor. Soc. Jpn., 85A, 337-361, 2007.

Gautam, R., Hsu, N. C., Kafatos, M., and Tsay, S.-C.: Influences of winter haze on fog/low cloud over the Indo-Gangetic plains, J. Geophys. Res., 112, D05207, doi:10.1029/2005JD007036, 2007.

Gautam, R., Hsu, N. C., Lau, K. M., Tsay, S. C., and Kafatos, M.: Enhanced pre-monsoon warming over the Himalayan-Gangetic region from 1979-2007, Geophys. Res. Let., 36, L07704, doi:10.1029/2009GL037641, 2009a.

Gautam, R., Liu, Z., Singh, R. P., and Hsu, C. N.: Two contrasting dust-dominant periods over India observed from MODIS and CALIPSO data. Geophys. Res. Lett., 36, L06813, doi:10.1029/2009GL036967, 2009b.

Gautam, R., Hsu, N. C., Kafatos, M., and Tsay, S. C.: Aerosol and rainfall variability over the Indian monsoon region: distributions, trends and coupling, Ann. Geophys., 27, 3691-3703, doi:10.5194/angeo-27-3691-2009, 2009c.
Giovannettone, J. P. and Barros, A. P.: A Remote Sensing Survey of the Role of Landform on the Organization of Orographic Precipitation in Central and Southern Mexico, J. Hydromet., 9, 12671283, 2008.

Hindman, E. E. and Upadhyay, B. P.: Air pollution transport in the Himalayas of Nepal and Tibet during the 1995-1996 dry season, Atmos. Environ., 36, 727-739, 2002.

Huffman, G. J., Adler, R. F., Curtis, S., Bolvin, D. T., and Nelkin, E. J.: Global Rainnfall Analysis at Monthly and 3-h Time Scales., Adv. Global Change Res., 28, 291-305, 2007.

Findlater, J.: A major low-level air current near the Indian Ocean during the northern summer., Q. J. Roy. Meteorol. Soc., 95, 404, 362-380, 1963.

Hsu, N. C., Herman, J. R., Torres, O., Holben, B. N., Tanre, D., Eck, T. F., Smirnov, A., Chatenet, B., and Lavenu, F.: Comparisons of the TOMS aerosol index with Sun-photometer aerosol optical thickness: Results and applications. J. Geophys. Res., 104(D6), 6269-6279, 1999.

Hsu, N. C., Tsay, S. C., King, M. D., and Herman, J. R.: Aerosol properties over bright-reflecting source regions, IEEE Trans. Geosci. Remote Sens., 42, 557-569, 2004.

Hubanks, King, Platnick, and Pincus: MODIS Atmosphere L3 Gridded Product Algorithm Theoretical Basis Document, ATBD Reference Number: ATBD-MOD-30, 2008.

Kansakar S. R., Hannah, D. M., Gerrard, J., and Rees, G.: Spatial Pattern in the precipitation regime of Nepal, Int. J. Climatol., 24, 1645-1659, 2004.

King M. D., Tsay, S.-C., Platnick, S. E., Wang, M., and Liou, K.N.: Cloud Retrieval Algorithms for MODIS: Optical Thickness, Effective Particle Radius, and Thermodynamic Phase, Products: 06 L2, 08 D3, 08 E3, 08 M3, ATBD Reference Number: ATBDMOD-05, 1998.

King, M. D., Menzel, W. P., Kaufman, Y. J., Tanre, D., Gao, B.C., Platinick, S., Ackerman, S. A., Remer, L. A., Pincus, R., and Hubanks, P. A.: Cloud and Aerosol Properties, Precipitable Water, and Profiles of Temperature and Water Vapor from MODIS, IEEE Trans. Geosci. Remote Sens., 41(2), 442-458, 2003.

Krishnamurthy, V. and Shukla, J.: Intraseasonal and Interannual Variability of Rainfall over India, J Climate, 13, 4366-4377, 2000.

Lang, T. J. and Barros, A. P.: An Investigation of the Onsets of 1999 and 2000 Monsoons in Central Nepal, Mon. Weather Rev., 130, 1299-1316, 2002.

Lau, K.-M. and Kim, K.-M.: Observational relationship between aerosol and Asian monsoon rainfall, and circulation, Geophys. Res. Lett., 33, L21810, doi:10.1029/2006GL027546, 2006.

Lau, K. M., Kim, M. K., and Kim, K. M.: Asian summer monsoon anomalies induced by aerosol direct forcing: the role of the Tibetan Plateau, Clim. Dynam., 26, 855-864, 2006.

Lau, K.-M., Ramanathan, V., Wu, G.-X., Li, Z., Tsay, S. C., Hsu, C., Sikka, R., Holben, B., Lu, D., Tartari, G., Chin, M., Koudelova, P., Chen, H., Ma, Y., Huang, J., Taniguchi, K., and Zhang, R.: The joint aerosol-monsoon experiment: a new challenge for monsoon climate research, B. Am. Meteorol. Soc., 89, 369-383, 2008.

Liu, Z., Liu, D., Huang, J., Vaughan, M., Uno, I., Sugimoto, N., Kittaka, C., Trepte, C., Wang, Z., Hostetler, C., and Winker, D.: Airborne dust distributions over the Tibetan Plateau and surrounding areas derived from the first year of CALIPSO lidar obser- 
vations, Atmos. Chem. Phys., 8, 5045-5060, doi:10.5194/acp-85045-2008, 2008.

Perry A. M. and Neimann J. D.: Analysis and estimation of soil moisture at catchment scale using EOFs, J. Hydrol., 334, 388404, 2007.

Ramana, M. V., Ramanathan, V., and Podgorny, I. A., Pradhan, B. B., and Shrestha, B.: The direct observations of large aerosol radiative forcing in the Himalayan region, Geophys. Res. Lett., 31, L05111, doi:10.1029/2003GL018824, 2004

Ramanathan, V., Crutzen, P.J., Kiehl, J. T., and Rosenfeld, D.: Aerosols, Climate, and the Hydrological Cycle, Science, 294, 2119, doi:10.1126/science.1064034, 2001.

Ramanathan V. and Ramana, M. V.: Persistent, Widespread, and Strongly Absorbing Haze Over the Himalayan Foothills and the Indo-Gangetic Plains, Pure and Appl. Geophys., 162, 16091626, 2005.

Regmi, R. P., Kitada, T., and Kurata, G.: Numerical Simulation of Late Wintertime Flows in Kathmandu Valley, Nepal: Implication of Air Pollution Transport, J. App. Meteor., 42, 389-403, 2003.

Shrestha, A. B., Wake, C. P., Dibb, J. E., Mayewski, P. A., Whitlow, S. I., Carmichael, G. R., and Ferm, M.: Seasonal variations in aerosol concentrations and compositions in the Nepal Himalaya, Atmos. Environ., 34, 3349-3363, 2000.
Shrestha, M. L.: Interannual variation of summer monsoon rainfall over Nepal and its relation to Southern Oscillation Index, Meteo. Atmos. Phys., 75, 21-28, 2000.

Stone, E. A., Schauer, J. J., Pradhan, B. B., Dangol, P. D., Habib, G., Venkataraman, C., and Ramanathan, V.: Characterlization of emissions from South Asian biofuels and application to source apportionment of carbonaceous aerosol in the Himalayas, J. Geophys. Res.-Atmos., doi:10.1029/2009JD012514, in press, 2009.

Torres, O., Bhartia, P. K., Hermen, J. R., Sinyuk, A., Ginoux, P., and Holben, B.: A long term record of Aerosol Optical Depth from TOMS observations and comparison to Aeronet Observations, J. Atmos. Sci., 59, 398-413, 2002.

Tripathi, S. N., Pattnaik, A., and Dey, S.: Aerosol indirect effect over Indo-Gangetic plain, Atmos. Environ., 41, 7037-7047, 2007.

Von Storch, H. and Zwiers, F. W.: Statistical Analysis in Climate Research, Cambridge University Press, 293-301, 1999.

Wu, Y., Raman, S., Mohanty, and U. C.: Numerical Investigation of the Somali Jet Interaction with the Western Ghat Mountains, Pure Appl. Geophys., 154, 365-396, 1999. 